\title{
Catéter venoso periférico, medidas de bioseguridad
}

\author{
Venous Catheter, Safety Measures
}

Rocío B. Mayorga-Ponce ${ }^{a}$, Evila Gayosso-Islas ${ }^{b}$, Daniela Salazar-Valdez ${ }^{c}$, Abigail Martínez-

$$
\text { Alamilla }^{d} \text {, Ulises I. Mota-Velázquez }{ }^{e} \text {. }
$$

\begin{abstract}
:
In Mexico, 85 to $90 \%$ of patients who enter a hospital require a peripheral or central vascular access, which is why the Epidemiology General Directorate, through the Hospital Epidemiological Surveillance Network (RHOVE), implements biosecurity, these are a set of preventive actions that aim to protect the health and personal safety, the users and the related community, the biological, physical, chemical and mechanical risks. Biosecurity measures significantly influence the health of patients, are used in all techniques performed by the nursing staff, responsible for the installation, handling and removal of poisons access.
\end{abstract}

\section{Keywords:}

Biosafety, health, risk, catheter, infection

\section{Resumen:}

En México de 85 a 90\% de los pacientes que ingresan a un centro hospitalario requieren de un acceso vascular periférico o central es por eso que la Dirección General de Epidemiologia, a través de la Red Hospitalaria de Vigilancia Epidemiológica (RHOVE) implementa las medidas de bioseguridad, estas son un conjunto de acciones preventivas que tienen como objetivo proteger la salud y la seguridad del personal, los usuarios y la comunidad relacionada, frente a diferentes riesgos producidos por agentes biológicos, físicos, químicos y mecánicos. Las medidas de bioseguridad influyen de manera significativa en la salud de los pacientes, son empleadas en todas las técnicas realizadas por el personal de enfermería, encargado de la instalación, manejo y retiro de los accesos venosos

\section{Palabras Clave:}

Bioseguridad, salud, riesgo, catéter, infección

\section{Introducción}

La instalación de catéter venoso periférico es el procedimiento por medio del cual, se introduce un catéter en una vena, para la administración directa al torrente sanguíneo de fluidos, componentes sanguíneos y/o medicamentos, que permitan restablecer o conservar el equilibrio hidroelectrolítico y hemodinámico del paciente. Dichas instalaciones son procedimientos invasivos por lo que son puerta de ingreso para virus y bacterias.

Las infecciones causadas por una incorrecta técnica al instalar y/o manejar el catéter venoso periférico alargan la estancia hospitalaria del paciente y por ende elevan los costos en salud, además que colocan al paciente en un riesgo alto de padecer distintos tipos de complicaciones. Al poner en práctica las medidas de bioseguridad el personal de enfermería garantiza la reducción de posibilidades que el paciente pase por un cuadro infeccioso causado por la instalación del catéter periférico, además que el personal de enfermería protege su integridad al usar estas medidas.

\footnotetext{
a Autor de Correspondencia, Universidad Autónoma del Estado de Hidalgo, Instituto de Ciencias de la Salud, ORCID: https://orcid.org/00000003-3544-7171, Email: robel62@ hotmail.com

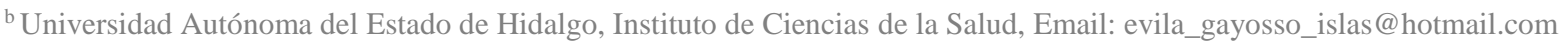

c Universidad Autónoma del Estado de Hidalgo, Instituto de Ciencias de la Salud, Email: danielasalazar457@ gmail.com

d Universidad Autónoma del Estado de Hidalgo, Instituto de Ciencias de la Salud, Email: abigailmartinez5809@ gmail.com 


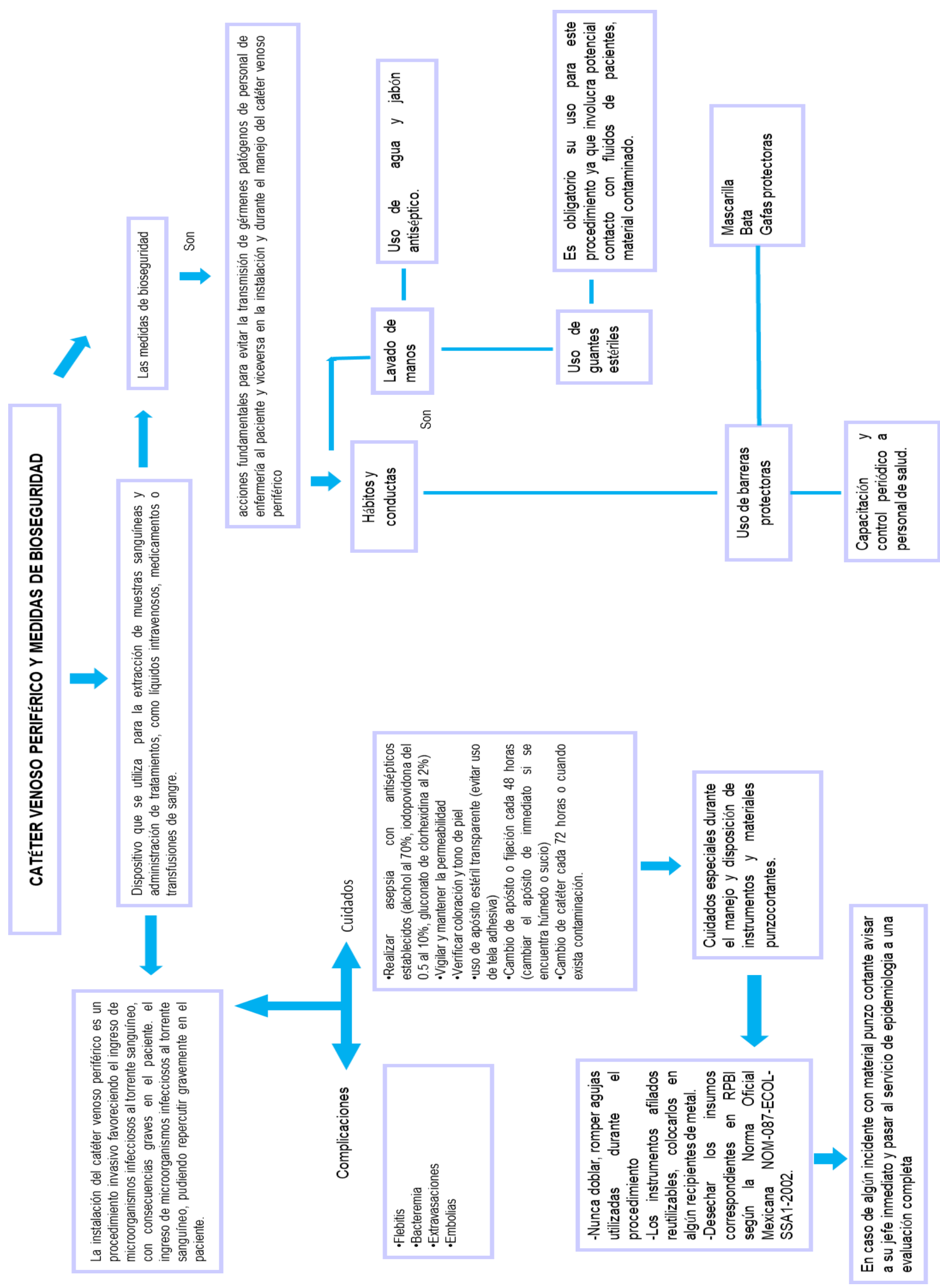




\section{Referencias}

[1] Accidentes, C. (2017). Medidas de bioseguridad en los establecimientos de salud. [Online]. Revisita salud laboral.

[2] Secretaria de Salud. (2011). Protocolo para el manejo estandarizado del paciente con catéter periférico, central y permanente. [Online]. Secretaria de salud Jalisco.

[3] Raimundo Gómez K. (2015). Calidad de cuidado de enfermería en el manejo de catéter periférico en hospitales de Huánuco. [Online]. Escuela académico profesional de enfermería.

[4] Cifuentes Valdivia L. (2015). Protocolo de instalación y manejo de vías venosas periféricas. [Online]. Hospital Iquique.

[5] Rodríguez, J. (2017). El acceso venoso periférico y sus repercusiones en la salud de pacientes de emergencia en el Hospital "Delfina Torres de Concha" Esmeraldas 2016. [Online]. Repositorio Digital Universidad Técnica del Norte. 